\title{
AXIAL COMPRESSION STABILITY OF A CRISSCROSS SECTION COLUMN COMPOSED OF CONCRETE-FILLED SQUARE STEEL TUBES
}

\author{
Chen Zhi-HuA, Rong Bin And Apostolos Fafitis
}

\begin{abstract}
A crisscross section column composed of concrete-filled square steel tubes was tested in axial loading up to failure. The column was analyzed by the finite element method and the ultimate load as well as the failure mode were in agreement with the experimental findings. An analytical method was also proposed which when applied to the tested column gave an estimate of the ultimate load about $4 \%$ different from the experimental. The analytical method also predicted the mode of failure correctly.
\end{abstract}

\section{Introduction}

Special-shaped columns have found applications in many structures, especially residential buildings. Compared with regular columns, special-shaped columns have the distinguishing characteristic of flexible sections such as $L$-shaped, $T$-shaped, and crisscross sections. The use of special-shaped columns in residential buildings can give more indoor space than regular rectangular or square columns.

The behavior of special-shaped reinforced concrete columns has been the subject of investigation and many experimental and analytical studies have been published. Ramamurthy and Hafeez Khan [1983] have proposed a method to determine the theoretical ultimate loads of $L$-shaped concrete columns based on the concept of an equivalent square or rectangular column. Hsu [1985; 1989] has presented theoretical and experimental results for $L$-shaped and $T$-shaped reinforced concrete sections. Mallikarjuna and Mahadevappa [1992; 1994] have carried out numerical investigations on the strength of $L$-shaped and $T$-shaped short reinforced concrete columns that have been subjected to combined axial loading and bending in order to provide design aids for structural engineers. Tsao and Hsu [1993; 1994] have presented an experimental and analytical investigation of the strength and deformation behavior of biaxially loaded slender and tied columns with $L$-shaped cross sections. Dundar et al. [2008; Dundar and Sahin 1993] have studied reinforced concrete $L$-shaped sections under biaxial bending and axial loads. Demagh et al. [2005] have carried out numerical investigations for the analysis and the design of $L$-shaped short reinforced concrete columns subjected to combined axial loads and bending based on the fiber method. Tokgoz and Dundar [2008] have studied the behavior of concrete-encased composite columns with $L$-shaped sections under short-term axial loads and biaxial bending by means of both experiment and theoretical analysis. For determination of the behavior of eccentrically loaded short and slender composite columns, a theoretical procedure considering the nonlinear behavior of the materials has been proposed.

\footnotetext{
Keywords: crisscross section composite column, concrete-filled square steel tubes, stability, axial compression experiment,
} finite element analysis, analytical method.

This research was supported by the Chinese Program for New Century Excellent Talents in University. The financial support is greatly appreciated. 

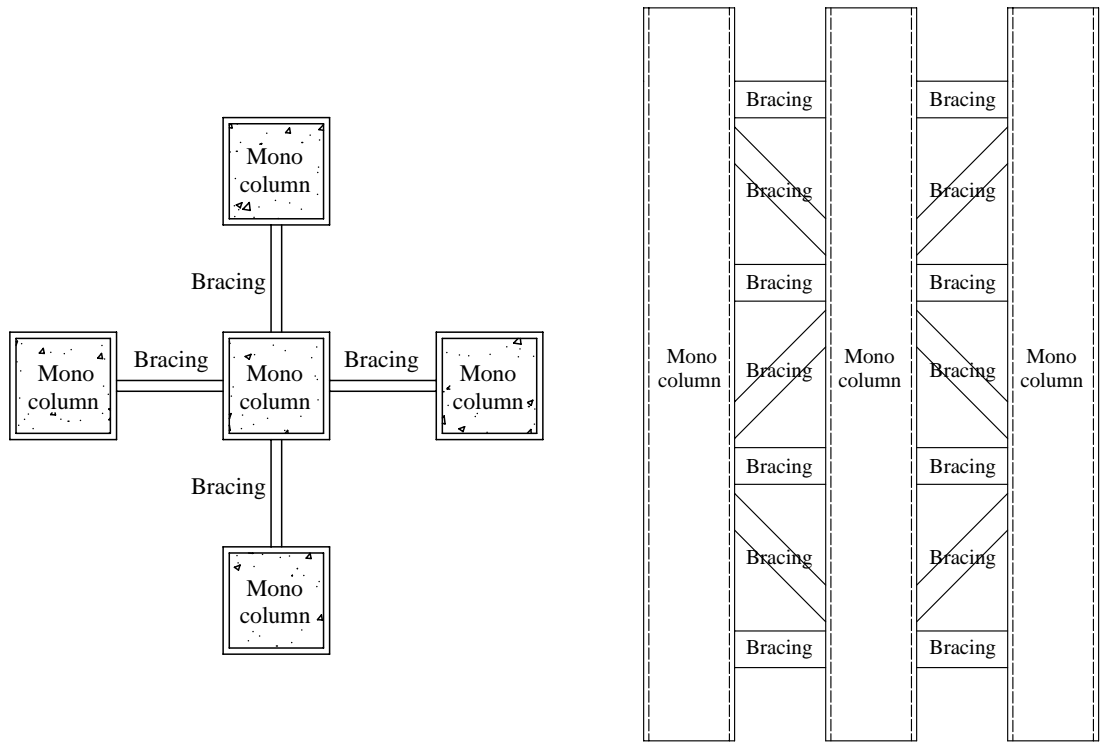

Figure 1. Schematic of a XCFST column.

In recent years, concrete-filled square steel tubular (CFST) columns have been widely used in the construction of buildings due to their excellent static and earthquake-resistant properties, such as high strength, high ductility, and large energy dissipation capacity. A large number of studies have been carried out on CFST columns. Several surveys on CFST structures have also been published [Han 2002; Tsai et al. 2003; Sakino et al. 2004; Fujimoto et al. 2004; Han et al. 2008]. By contrast, special-shaped columns consisting of CFST columns have not been studied. The focus of this investigation is a new type of crisscross section column composed of concrete-filled square steel tubes (XCFST) made up of five CFST columns with steel bracing connections as shown in Figure 1. Since each monocolumn is a CFST column, the whole XCFST column also has better static, earthquake, and fire resistance behavior.

Compared to regular columns, as shown in Figure 2, each monocolumn of an XCFST column has a smaller section. Therefore, in residential buildings, they can be embedded in walls so as to avoid convex corners indoors and to enlarge the usable interior area.

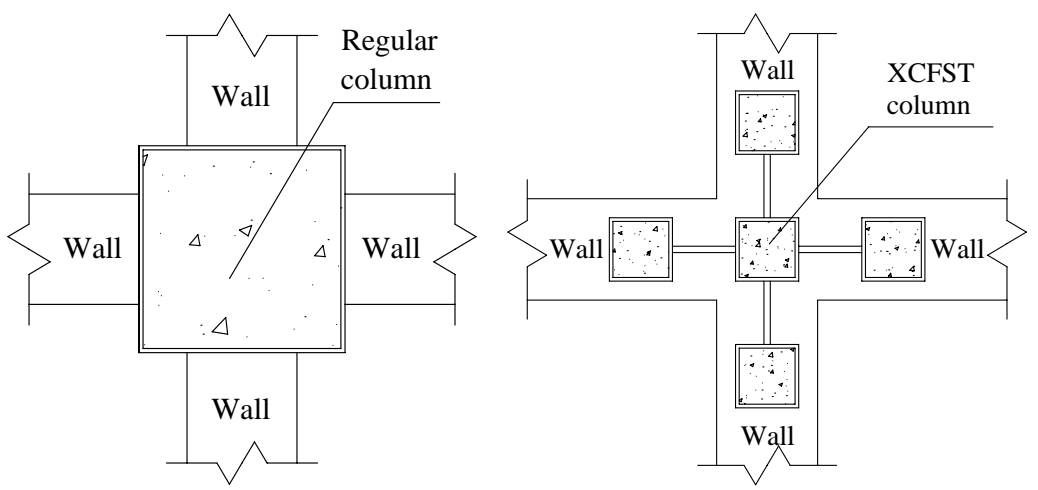

Figure 2. Applications of a regular column and an XCFST column. 
The objectives of this study are to determine the maximum load-bearing capacity of an XCFST column subjected to axial compression and to investigate the failure pattern up to the ultimate load. We adopted a three-pronged approach: experiment, analytical study, and finite element simulation. Specifically, we report the experimental test results of an XCFST column under axial compression, use finite element modeling to analyze the process, and develop a method for calculating the maximum load-bearing capacity of an XCFST column under axial compression. All three approaches were applied to the same model, which we describe in the next section.

\section{Experimental work}

The specimen. The specimen in the experimental study was an XCFST column that was two meters long with square steel tubes of $100 \mathrm{~mm} \times 100 \mathrm{~mm} \times 5.75 \mathrm{~mm}$. The horizontal bracings were $100 \mathrm{~mm} \times$ $40 \mathrm{~mm} \times 10 \mathrm{~mm}$, and the diagonal bracings were $142 \mathrm{~mm} \times 28 \mathrm{~mm} \times 10 \mathrm{~mm}$ at $45^{\circ}$.

The manufacturing process of the specimen was as follows. The tubes were all manufactured from steel plates, with the plates being tack welded into a square shape. After this, the square steel tubes and bracings were cut and welded together. A $10 \mathrm{~mm}$ thick steel plate was welded on the bottom of the specimen. Concrete was cast and consolidated in the square steel tubes tightly. After curing, a layer of cement mortar was used as a cap so that the concrete surface was flush with the steel tube at the top. Finally another $10 \mathrm{~mm}$ thick steel plate was welded at the top of the specimen. The specimen is shown in Figure 3, left.

Material properties. To determine the steel properties of the square tubes and the bracings, tension coupons were cut and tested in tension. For the square tubes, the average yield strength was $229 \mathrm{MPa}$, the ultimate strength $429 \mathrm{MPa}$, and the modulus of elasticity $1.89 \times 10^{5} \mathrm{MPa}$. For the bracings, the average yield strength was $274 \mathrm{MPa}$, the ultimate strength $415 \mathrm{MPa}$, and the modulus of elasticity $4.11 \times 10^{5} \mathrm{MPa}$.
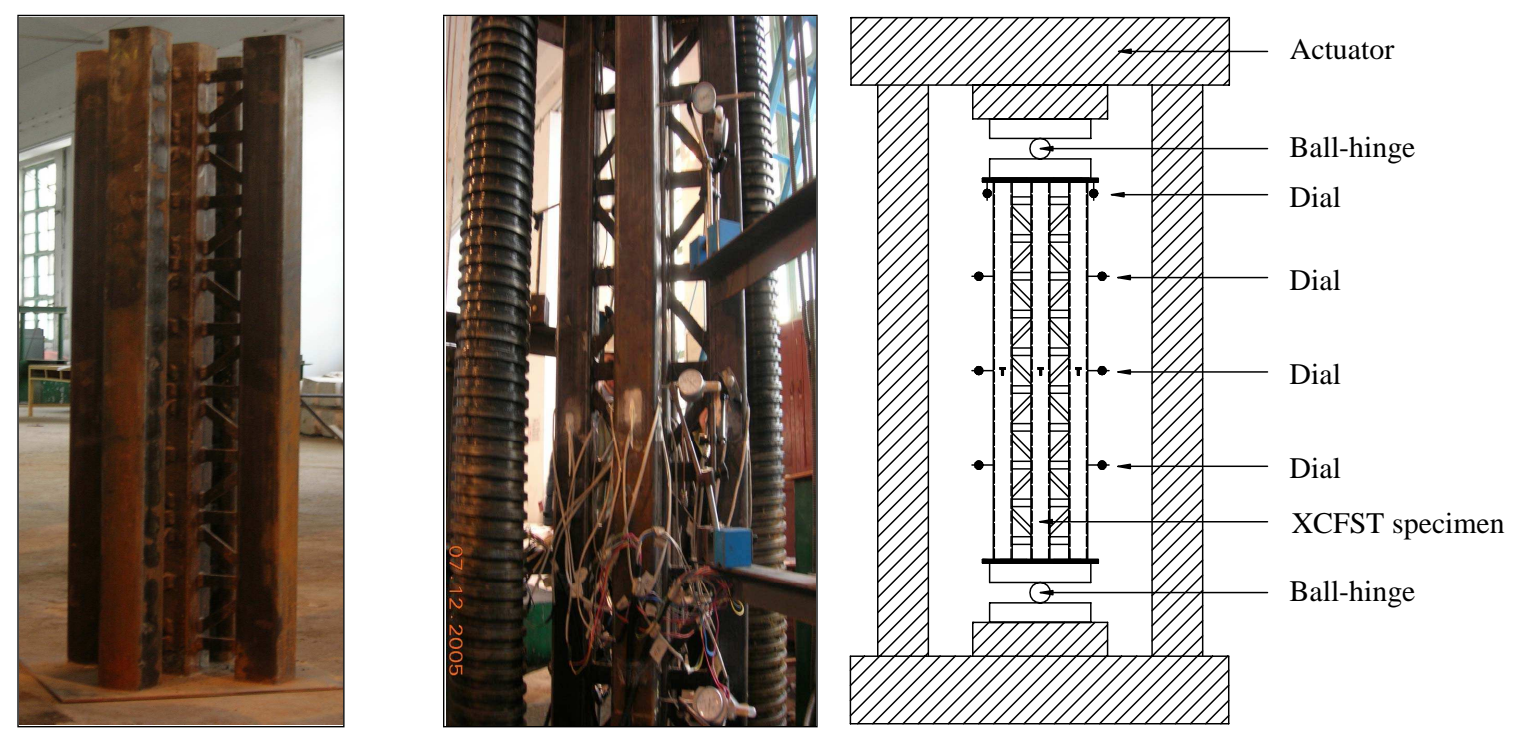

Figure 3. Left: The XCFST specimen. Middle and right: Test setup for the specimen. 
To determine the concrete material properties, three $150 \times 150 \times 150 \mathrm{~mm}$ cubes were cast and cured in conditions similar to that of the experiment. The mix proportions of concrete were cement $353 \mathrm{~kg} / \mathrm{m}^{3}$, water $175 \mathrm{~kg} / \mathrm{m}^{3}$, sand $696 \mathrm{~kg} / \mathrm{m}^{3}$, and coarse aggregate $1088 \mathrm{~kg} / \mathrm{m}^{3}$. The average crushing strength of these concrete cubes after 28 days was $49.7 \mathrm{MPa}$ and the modulus of elasticity was $4.33 \times 10^{4} \mathrm{MPa}$.

Test procedure. The XCFST specimen was tested with pinned conditions at both ends using a $5000 \mathrm{kN}$ capacity axial actuator. The testing setup for the XCFST specimen is shown in Figure 3, middle and right.

The specimen was loaded until it reached the failure point. A load interval of about one tenth of the estimated carrying load capacity was used. Each load interval was maintained for about 2-3 minutes. The progress of deformation, the mode of failure, and the maximum load taken by the specimen were recorded continuously.

During the test, the load level was controlled by the actuator. The lateral dials monitored the deflection of the monocolumns. The vertical dials recorded the displacement of the XCFST column. The location of the instrumentation is shown in Figure 4, left. The labels 1, 4, 7, and 10 indicate the lateral dials attached at $1.5 \mathrm{~m}$ from the ground plate; 2, 5, 8, and 11 indicate the lateral dials at $1.0 \mathrm{~m}$, which is the middle height of each monocolumn; 3, 6, 9, and 12 indicate the lateral dials at $0.5 \mathrm{~m}$; and 13 and 14 indicate the vertical dials in the top plate of the XCFST column.

Test results. The test was stopped when the XCFST column reached the ultimate bearing capacity. The deformation of failure was very small. Figure 4, right, shows the failure mode of the XCFST column, and as shown there were small deformations of each monocolumn.

Load versus axial shortening. The load versus shortening curve provides information on the ultimate carrying capacity of the XCFST column specimen.
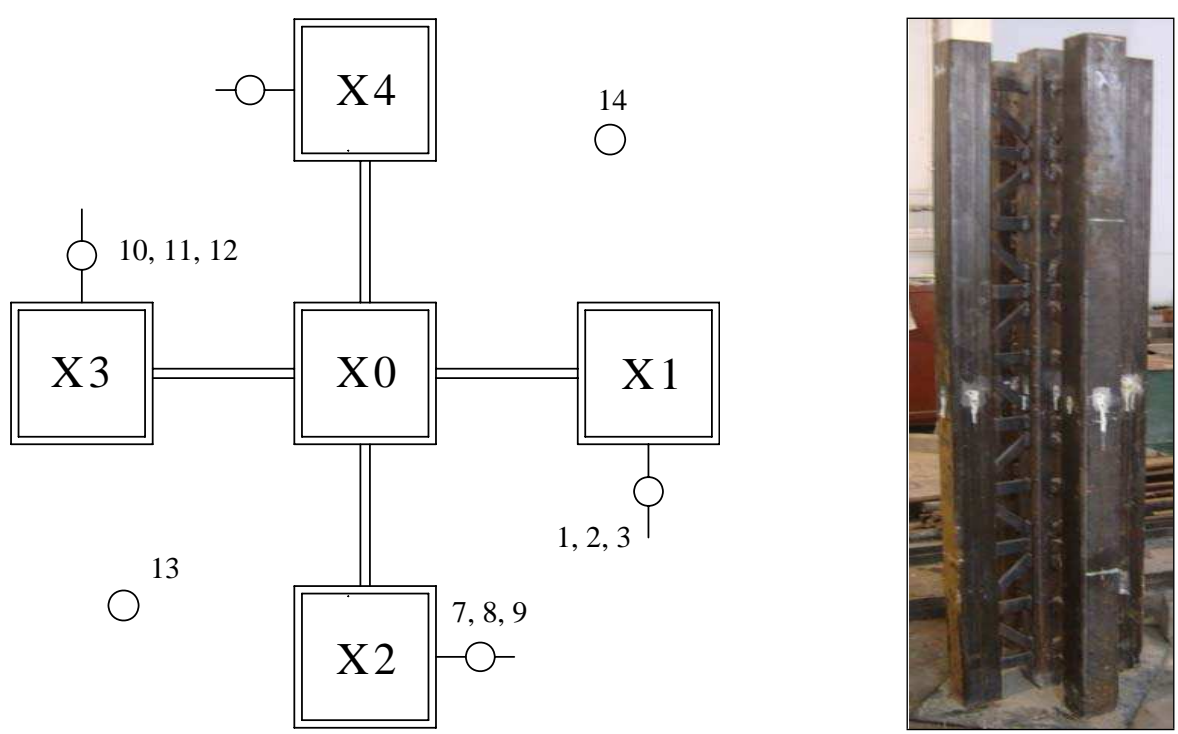

Figure 4. Left: positions of dial indicators. Right: Deformation of the XCFST specimen. 


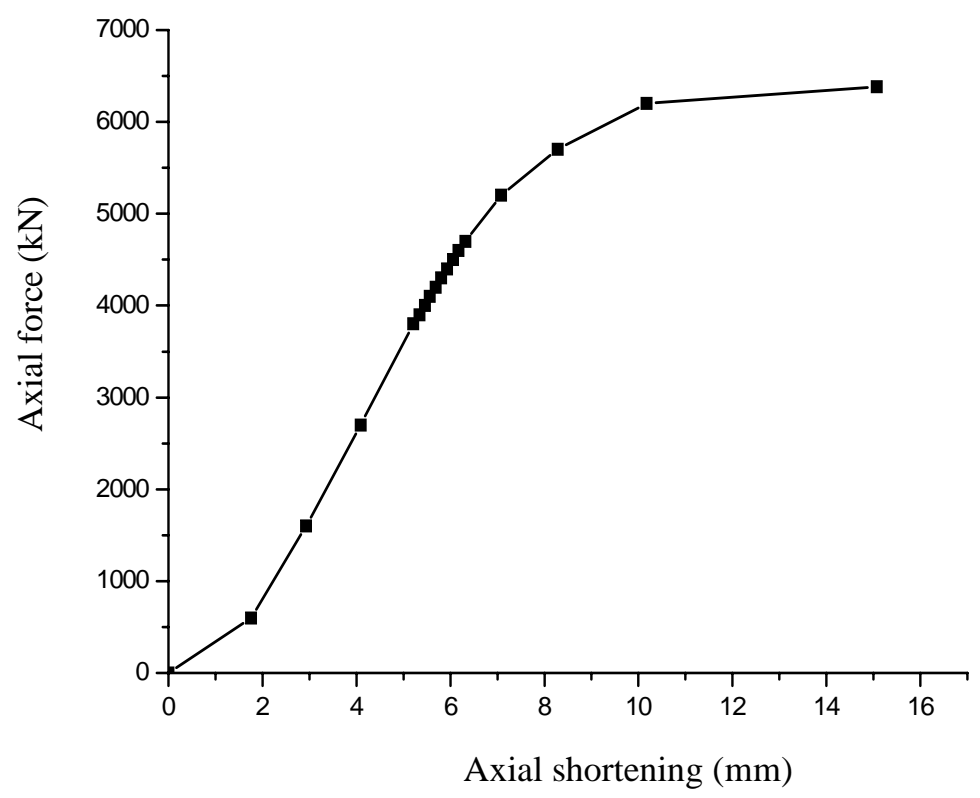

Figure 5. Axial load versus shortening curve of the XCFST specimen.

Figure 5 shows the relation of the axial force and axial shortening of the XCFST specimen. Note that up to about $6100 \mathrm{kN}$, the behavior was almost linear. Beyond this load, the XCFST column entered the bulking stage. Finally at a load of $6390 \mathrm{kN}$, the shortening was $15.2 \mathrm{~mm}$ and the test was stopped.

Deflection of monocolumn. Figure 6 shows the deformation history of each monocolumn. The number in parenthesis identifies the dials (for example, 1, 2, and 3). The load level designation from $600 \mathrm{kN}$ to $6390 \mathrm{kN}$ is shown in the box next to the profile of the column.

According to Figure 6, at the failure load of $6390 \mathrm{kN}$, the deflection of monocolumn X3 was the largest of the four monocolumns. The failure process was initiated by the buckling of monocolumn X3.

Discussions of experimental behavior of specimen. From the load-deformation curve, it is apparent that for a load less than about $6100 \mathrm{kN}$ the XCFST column remains in the elastic range. This is true for the monocolumns X2, X3, and X4. For a load above $6100 \mathrm{kN}$ the column enters gradually into the buckling stage and the load-deformation curve deviates from linearity. At a load of $6390 \mathrm{kN}$, the XCFST column has reached its ultimate capacity. Finally it appears that the failure process is initiated by the buckling of monocolumn X3.

\section{Finite element analysis}

General. The commercial finite element software ANSYS has been used to simulate the axial compression experiment of the XCFST specimen as described before. There are three main components that need to be modeled in order to simulate the behavior of the XCFST column. These are the steel tubes and bracings, the infilled concrete, and the interface between the concrete and the steel tube. In addition, the choice of the element type, the mesh size, the initial geometric deformation, the boundary conditions, and the load application are also important in simulating the special-shaped column. 


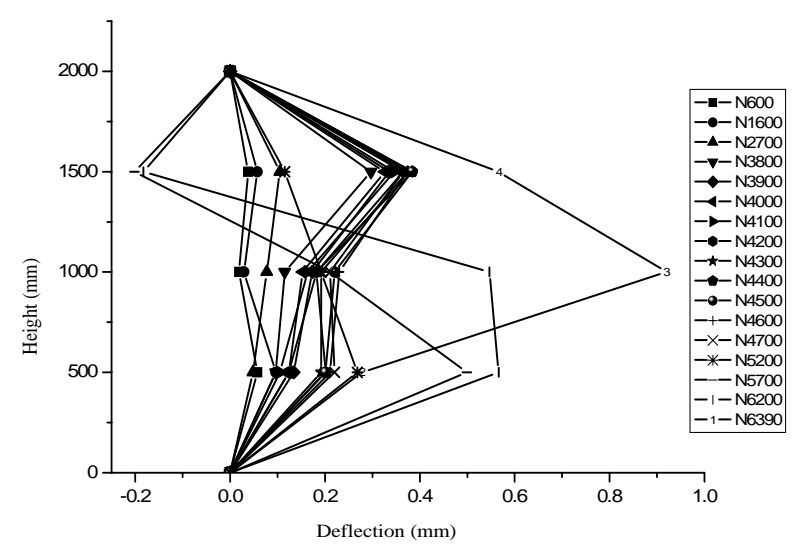

Monocolumn X1 $(1,2,3)$

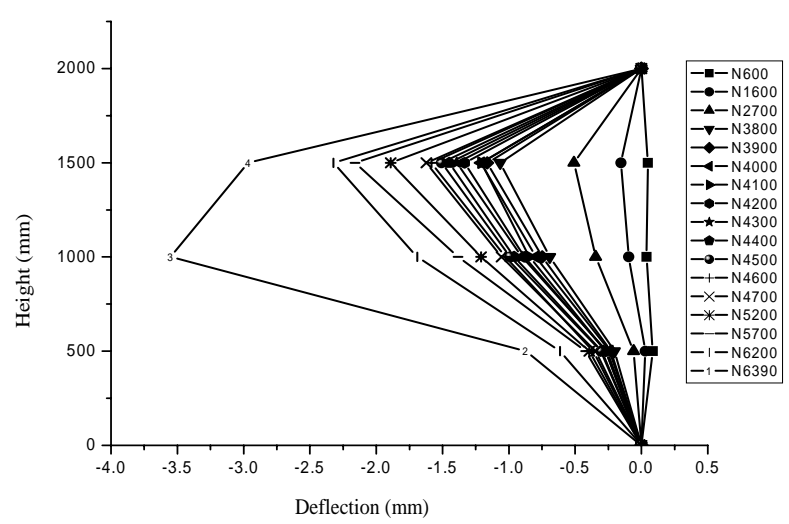

Monocolumn X3 $(10,11,12)$

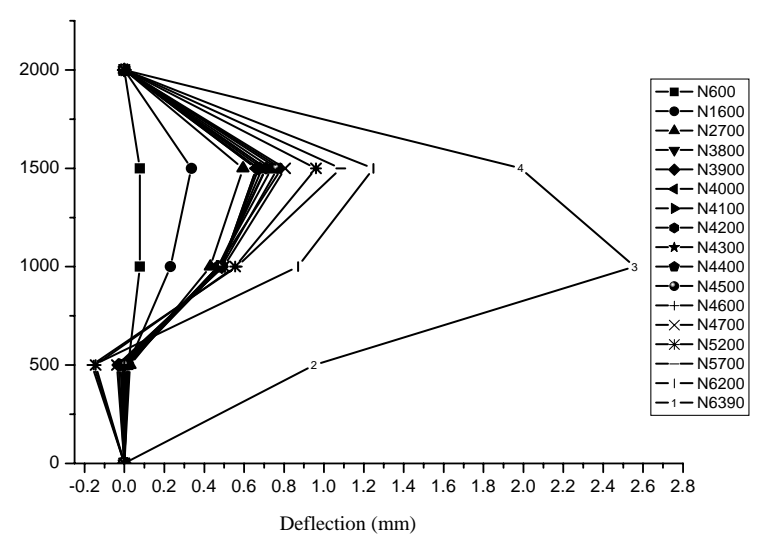

Monocolumn X2 $(7,8,9)$

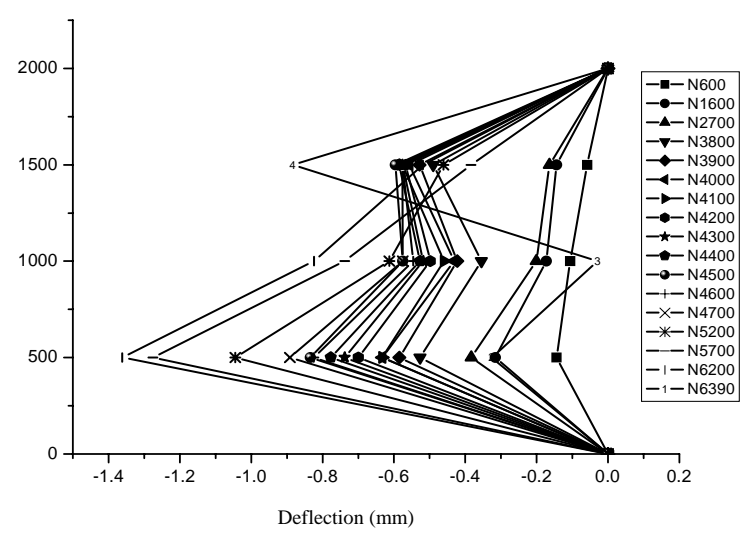

Monocolumn X4 $(4,5,6)$

Figure 6. Deflection of single concrete-filled square steel tubes.

Modeling of the steel tubes and bracings. In this simulation, the element SHELL 181 was used to model the steel tubes and bracings. SHELL 181 is a 4-node doubly curved shell element which has six degrees of freedom per node. This element's capacity for transverse shear deformation provides adequate accuracy in simulating the buckling behavior of the steel tubes.

The constitutive law of steel tubes and bracings [GB50017 2003] was assumed elastoplastic with yielding strain equal to $f_{y} / E_{s}$. The strain hardening was ignored and the Poisson's ratio was equal to 0.3. The idealized stress-strain curve used in the numerical analysis is shown in Figure 7, left.

Modeling of the concrete. The three-dimensional 8-node element SOLID 65 was adopted to model the infilled concrete. Each node of the element has three degrees of freedom. This element is capable of cracking, crushing, and plastic deformation and can achieve accurate results in simulating the behavior of concrete in axial loads.

The ratio of the thickness of the tube plates to the overall size of the tube cross section was not adequate to provide confinement. Therefore, the uniaxial stress-strain curve was adopted [Ellobody and Young 2006]. The constitutive law of concrete has two branches. The ascending branch was assumed to 

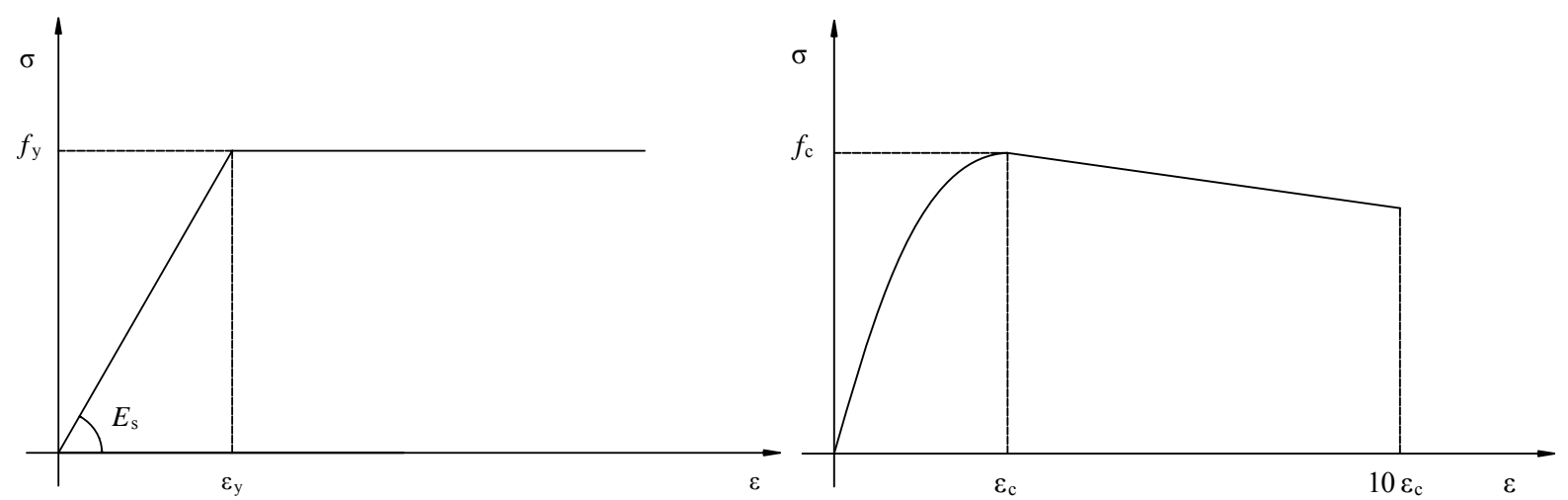

Figure 7. Left: constitutive law of steel tubes and bracings. Right: constitutive law of concrete.

be parabolic up to a strain equal to 0.003 and the descending branch was linear, as shown on the graph on the right in Figure 7.

Modeling of the concrete-steel tube interface. The contact action between the steel tube and the concrete was modeled by the contact elements TARGE 170 and CONTA 173. These surface-to-surface contact elements consist of two matching contact faces of the steel tube and concrete elements. The friction between the two faces is maintained as long as the surfaces remain in contact. The coefficient of friction between the two faces was taken as 0.25 in the analysis. These contact elements allow the surfaces to separate under the influence of tensile force. However, the contact elements are not allowed to penetrate each other.

Mesh size and initial geometrical deformation. Different mesh sizes have been tried to choose a reasonable mesh that can provide both accurate results and reasonable computational time. It was found that a mesh size of approximately 1:1:2 (length:width:depth) for solid elements and 1:1 (length:width) for shell elements can achieve accurate results. The coincident nodes between steel tubes and bracings were merged after all elements were meshed in order to ensure that the deformations of the steel tubes and bracings in such places were identical.

In practice, there are initial geometrical deformations in the XCFST specimen. Therefore the influence of initial geometrical deformation was considered in this simulation. For this purpose, a $1 \%$ initial deformation resembling the first-order buckling mode was introduced to the finite element modeling.

Boundary conditions and load application. Pinned boundary conditions were assumed. The top and bottom surfaces of the XCFST column were restrained in all translational degrees of freedom except for the displacement of the top plate in the direction of the applied load.

The load was applied as a static uniform load using the displacement control at each node of the loaded top surface, and the displacements were applied in incremental steps, which were identical to the steps of the experimental investigation.

The finite element model is shown in Figure 8.

Procedure verification. In order to validate the finite element analysis, recent axial compression experimental results on 42 concrete-filled square steel tubes conducted by Li et al. [1998] were compared with 

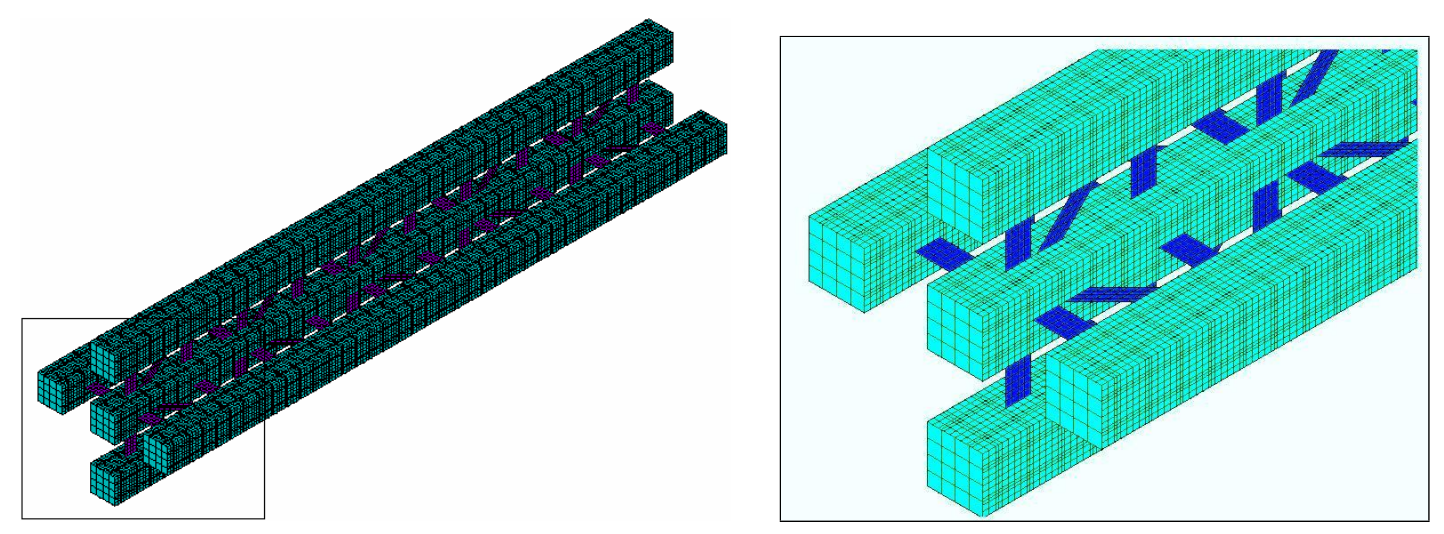

Figure 8. Finite element model.

the results of the finite element model in this study. The mean difference between the experiment data and the simulated results, shown in Figure 9, was less than 5\%.

Comparison of results. The force-deformation curve obtained by finite element analysis is shown in Figure 10. The ultimate capacity is $5929 \mathrm{kN}$. The failure mode is shown in Figure 11. It was found that the deformation of the monocolumns was in the flexure mode whereas the deformation mode of the XCFST column was very small.

Note that the experimentally obtained failure load $(6390 \mathrm{kN})$ compares well with the value predicted by finite element analysis $(5929 \mathrm{kN})$, with a difference of $7.2 \%$. Also the experimentally observed deformation models of the monocolumns and the XCFST column were the same as the ones predicted by finite element analysis.

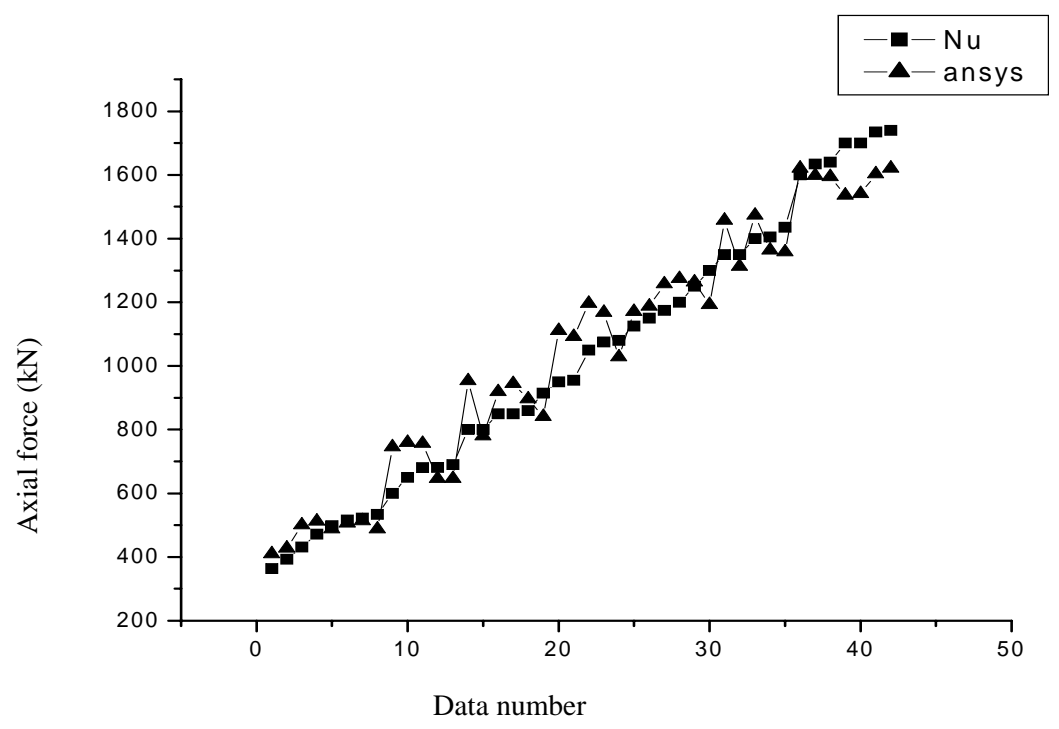

Figure 9. Comparison between testing data and calculated data by ANSYS. 


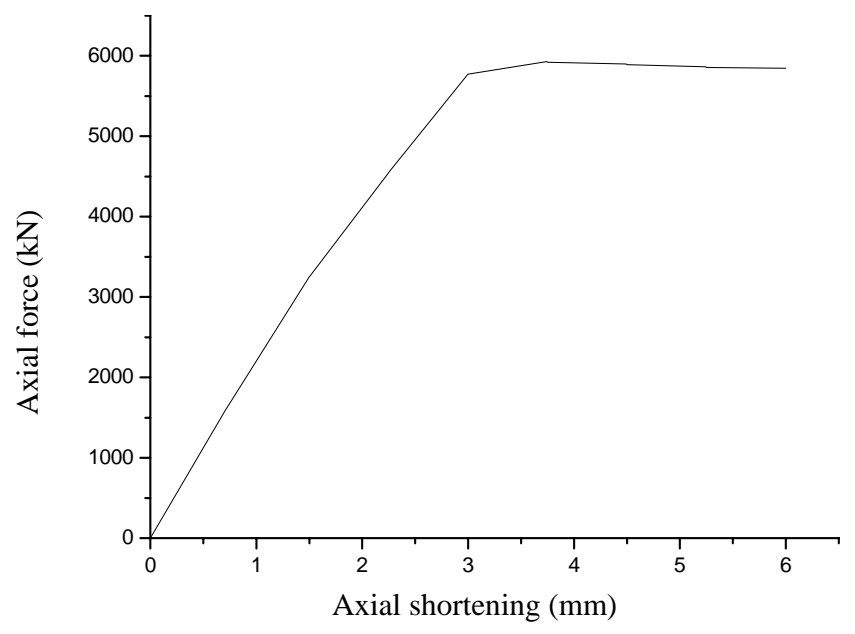

Figure 10. Load versus axial shortening curve.
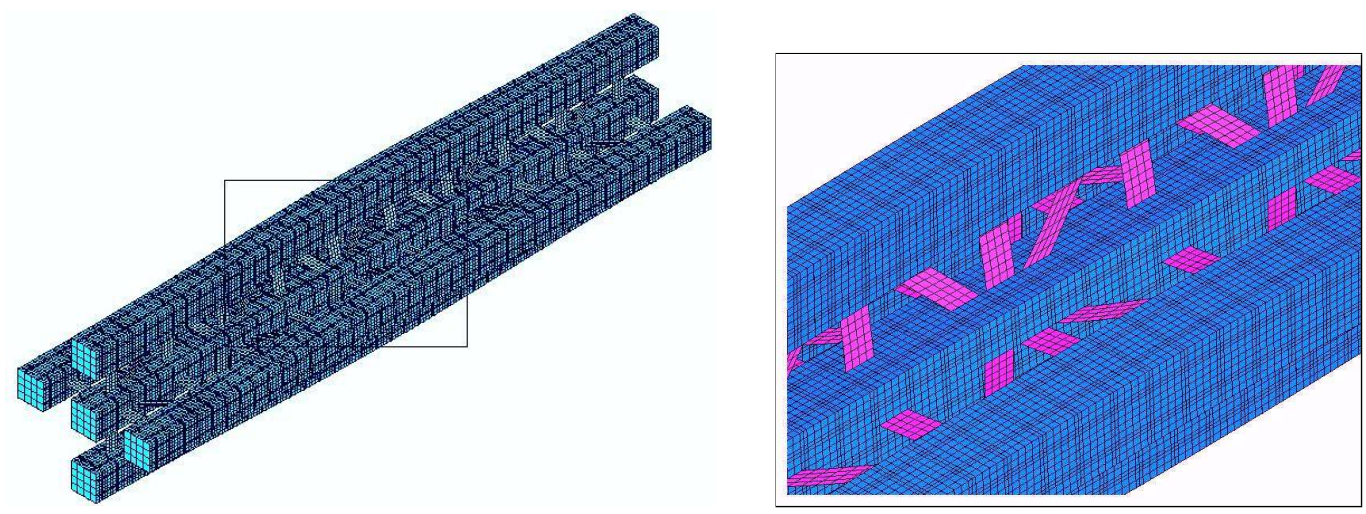

Figure 11. Failure mode of finite element model.

\section{Analytical evaluation of the axial capacity}

General. According to the Design Code for Steel Structures [GB50017 2003], the ultimate bearing capacity $N_{u}$, the sum of the capacities of the steel and the concrete, and the design capacity $N$ are given by

$$
N_{u}=\lambda \cdot f_{y} \cdot A_{s}+f_{c} \cdot A_{c}, \quad N \leq N_{u},
$$

where $\lambda$ is the stability factor, $f_{y}$ is the yield stress of the steel, $f_{c}$ is the axial strength of the concrete, $A_{c}$ is the cross sectional area of the concrete, and $A_{s}$ is the cross sectional area of the steel tube.

The slenderness ratio $\left(\lambda_{o}\right)$. In an XCFST, the shear stiffness of the bracings among the monocolumns is weak so that buckling may happen under axial compression and the calculation of the slenderness ratio of the XCFST is the key component in the superposition theory. 
The formula for $\lambda_{o}$ is derived based on the following assumptions: All three monocolumns have the same size and material properties for steel and concrete. The horizontal and diagonal bracings have the same size. The spatial truss model is employed for the analysis.

The slenderness ratio of a truss with pinned supporting condition is given by the theory of elastic stability [Leonard and George 2005]:

$$
\lambda_{o}=\sqrt{\lambda_{1}^{2}+\pi^{2} \gamma_{1} \sum_{i=1}^{n}\left(E_{s} A_{s i}+E_{c} A_{c i}\right)},
$$

where $\lambda_{o}$ is the slenderness ratio of the XCFST column, $\lambda_{1}$ is the slenderness ratio of the unbraced columns for the $x-x$ or $y-y$ axis as shown in Figure 12, $\gamma_{1}$ is the angle of unit shear as explained later (see (4)), $n$ is the number of monocolumns, $E_{s}$ is the steel modulus of elasticity, $A_{s}$ is the cross sectional area of the steel tubes, $E_{c}$ is the concrete modulus of elasticity, and $A_{c}$ is the cross sectional area of the concrete.

The derivation of the slenderness ratio for buckling is based on Figure 13. One half of the structure is shown in Figure 13c because of symmetry.

From Figure $13 \mathrm{~b}$ and $\mathrm{c}$, it can be seen that the axial force of the diagonal bracing $N_{d}$ is $N_{d}=\frac{1}{2 \sin \theta}$, where $\theta$ is the angle between the steel tube and the diagonal bracing.

The axial deformation of the diagonal bracing $\Delta_{d}$ is:

$$
\Delta_{d}=\frac{N_{d} l_{d}}{E_{S} A_{1}}=\frac{a}{2 E_{s} A_{1} \sin \theta \cos \theta},
$$

where $l_{d}$ is the length of the diagonal bracing, $a$ is the length of vertical projection for the diagonal bracing, and $A_{1}$ is the cross sectional area of the diagonal bracing.

Therefore, the angle of the unit shear is:

$$
\gamma_{1} \approx \frac{\Delta}{a}=\frac{\Delta_{d}}{a \sin \theta}=\frac{1}{2 E_{s} A_{1} \sin ^{2} \theta \cos \theta},
$$

where $\Delta$ is the length of horizontal projection of axial deformation for the diagonal bracing $\Delta_{d}$.

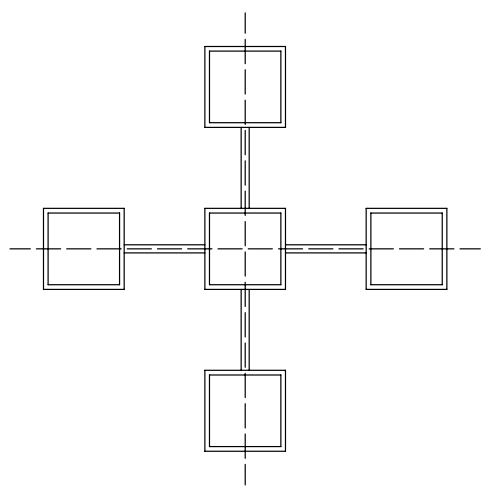

Figure 12. XCFST section inertia axis. 
Substituting $\gamma_{1}$ from (4) into (2), the equivalent slenderness ratio becomes:

$$
\lambda_{o}=\sqrt{\lambda_{1}^{2}+\frac{5 \pi^{2}\left(E_{s} A_{s}+E_{c} A_{c}\right)}{2 E_{s} A_{1} \sin ^{2} \theta \cos \theta}} .
$$

Application of the analytical method. The method explained in the previous paragraph will be applied to compute the ultimate axial capacity of the tested XCFST column.

With reference to the previous two subsections, the values of the structural parameters involved in Equations (1)-(5) are the following:

$$
\begin{array}{lllll}
n=5, & A_{s}=2167.75 \mathrm{~mm}^{2}, & A_{c}=7832.25 \mathrm{~mm}^{2}, & A_{1}=280 \mathrm{~mm}^{2}, & I=189526605 \mathrm{~mm}^{4}, \\
\theta=45^{\circ}, & f_{y}=429 \mathrm{~N} / \mathrm{mm}^{2}, & f_{c}=39.6 \mathrm{~N} / \mathrm{mm}^{2}, & E_{c}=43300 \mathrm{~N} / \mathrm{mm}^{2}, & E_{s}=189000 \mathrm{~N} / \mathrm{mm}^{2} .
\end{array}
$$

The length of the column is $2 \mathrm{~m}$. The size of the horizontal bracing is $100 \times 40 \times 10 \mathrm{~mm}$, and the diagonal bracing $142 \times 28 \times 10 \mathrm{~mm}$.

The slenderness ratios for the $x-x$ and $y-y$ axes respectively are

$$
i=\sqrt{\frac{I}{5 A_{s}}}=132 \mathrm{~mm}, \quad \lambda_{1}=\frac{l}{i}=\frac{2000}{132}=15 .
$$

With these values, the slenderness ratio in bending buckling is given by (5):

$$
\lambda_{o}=\sqrt{\lambda_{1}^{2}+\frac{5 \pi^{2}\left(E_{s} A_{s}+E_{c} A_{c}\right)}{2 E_{s} A_{1} \sin ^{2} \theta \cos \theta}}=35 .
$$

Based on the slenderness ratio $\lambda_{o}=35$, the stability factor $\lambda$ in (1) given as 0.918 in [GB50017 2003]. Therefore the ultimate capacity is

$$
N_{u}=5 \lambda f_{y} A_{s}+5 f_{c} A_{c}=5820 \mathrm{kN} .
$$

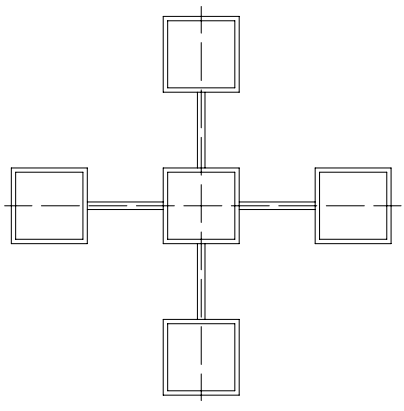

(a)

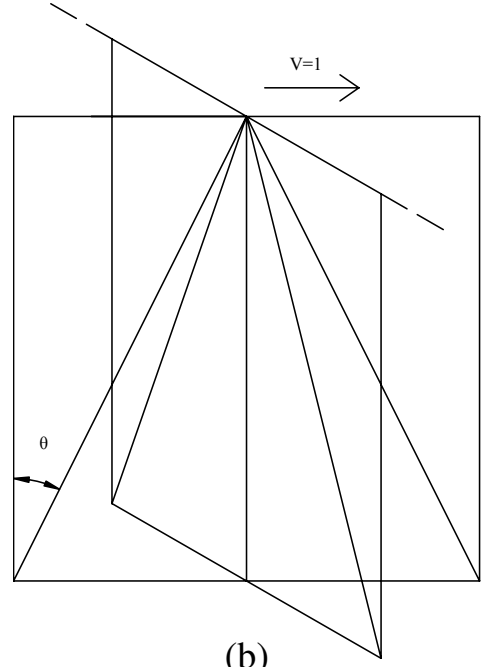

(b)

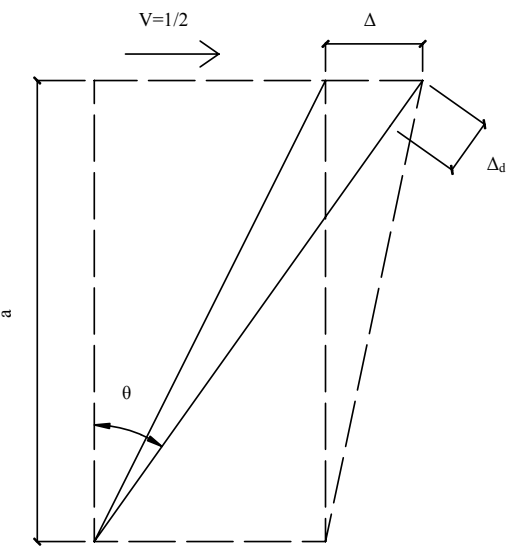

(c)

Figure 13. Calculation model of buckling. 


\section{Conclusions}

The ultimate capacity of a crisscross section column composed of concrete-filled square steel tubes (XCFST) was determined experimentally by finite element analysis and by the analytical method explained in this paper. It was found that the results are in agreement.

More specifically, the ultimate capacity of the XCFST specimen was found experimentally to be equal to $6390 \mathrm{kN}$. By finite element analysis, the ultimate capacity was evaluated to be equal to $5959 \mathrm{kN}$, a difference of $7.2 \%$. The value of the ultimate capacity predicted by the analytical method was $5820 \mathrm{kN}$, an $8.9 \%$ difference from the experimentally obtained value.

Based on the evidence presented in this paper, the analytical method predicts the ultimate capacity with adequate accuracy. The axial compression stability of an XCFST was studied, and the results of the analytical method and finite element analysis all show that the failure process of the XCFST specimen was initiated by the buckling of the monocolumn.

\section{References}

[Demagh et al. 2005] K. Demagh, H. Chabil, and L. Hamzaoui, "Analysis of reinforced concrete columns subjected to biaxial loads", pp. 433-440 in Concrete for transportation infrastructure (Dundee, 2005), edited by R. K. Dhir et al., Thomas Telford, London, 2005.

[Dundar and Sahin 1993] C. Dundar and B. Sahin, "Arbitrarily shaped reinforced concrete members subject to biaxial bending and axial load", Comput. Struct. 49:4 (1993), 643-662.

[Dundar et al. 2008] C. Dundar, S. Tokgoz, A. K. Tanrikulu, and T. Baran, "Behaviour of reinforced and concrete-encased composite columns subjected to biaxial bending and axial load", Build. Environ. 43:6 (2008), 1109-1120.

[Ellobody and Young 2006] E. Ellobody and B. Young, "Nonlinear analysis of concrete-filled steel SHS and RHS columns", Thin-Walled Struct. 44:8 (2006), 919-930.

[Fujimoto et al. 2004] T. Fujimoto, A. Mukai, I. Nishiyama, and K. Sakino, "Behavior of eccentrically loaded concrete-filled steel tubular columns", J. Struct. Eng. (ASCE) 130:2 (2004), 203-212.

[GB50017 2003] Design code for steel structures, GB50017, China Planning Press, Beijing, 2003. In Chinese.

[Han 2002] L.-H. Han, "Tests on stub columns of concrete-filled RHS sections”, J. Constr. Steel Res. 58:3 (2002), 353-372.

[Han et al. 2008] L.-H. Han, W. Liu, and Y.-F. Yang, "Behaviour of concrete-filled steel tubular stub columns subjected to axially local compression”, J. Constr. Steel Res. 64:4 (2008), 377-387.

[Hsu 1985] C.-T. T. Hsu, "Biaxially loaded L-shaped reinforced concrete columns", J. Struct. Eng. (ASCE) 111:12 (1985), 2576-2595.

[Hsu 1989] C.-T. T. Hsu, "T-shaped reinforced concrete members under biaxial bending and axial compression”, ACI Struct. J. 86:4 (1989), 460-468.

[Leonard and George 2005] S. Leonard and F. George, Appied structural steel design, Tsinghua University Press, Beijing, 2005.

[Li et al. 1998] S. P. Li, H. D., Q. Wang, Y. C. Guo, and Y. Y. Huang, "Calculation for the ultimate bearing capacity of concrete filled steel tube columns under eccentric compression”, J. Build. Struct. 19:1 (1998), 41-51. In Chinese.

[Mallikarjuna and Mahadevappa 1992] Mallikarjuna and P. Mahadevappa, "Computer aided analysis of reinforced concrete columns subjected to axial compression and bending, I: L-shaped sections", Comput. Struct. 44:5 (1992), 1121-1138.

[Mallikarjuna and Mahadevappa 1994] Mallikarjuna and P. Mahadevappa, "Computer aided analysis of reinforced concrete columns subjected to axial compression and bending, II: T-shaped sections”, Comput. Struct. 53:6 (1994), 1317-1356.

[Ramamurthy and Hafeez Khan 1983] L. N. Ramamurthy and T. A. Hafeez Khan, "L-shaped column design for biaxial eccentricity”, J. Struct. Eng. (ASCE) 109:8 (1983), 1903-1917. 
[Sakino et al. 2004] K. Sakino, H. Nakahara, S. Morino, and I. Nishiyama, "Behavior of centrally loaded concrete-filled steeltube short columns", J. Struct. Eng. (ASCE) 130:2 (2004), 180-188.

[Tokgoz and Dundar 2008] S. Tokgoz and C. Dundar, "Experimental tests on biaxially loaded concrete-encased composite columns", Steel Compos. Struct. 8:5 (2008), 423-438.

[Tsai et al. 2003] K.-C. Tsai, Y.-T. Weng, M.-L. Lin, C.-H. Chen, J.-W. Lai, and P.-C. Hsiao, "Pseudo dynamic tests of a full scale CFT/BRB composite frame: displacement based seismic design and response evaluations", pp. 165-176 in Proceedings of the International Workshop on Steel and Concrete Composite Construction (IWSCCC-2003) (Taipei, 2003), edited by K.-C. Tsai and G.-Y. Liu, National Center for Research on Earthquake Engineering, Taipei, 2003. Report NCREE-03-026.

[Tsao and Hsu 1993] W. H. Tsao and C.-T. T. Hsu, "A nonlinear computer analysis of biaxially loaded L-shaped slender reinforced concrete columns”, Comput. Struct. 49:4 (1993), 579-588.

[Tsao and Hsu 1994] W. H. Tsao and C.-T. T. Hsu, "Behaviour of biaxially loaded square and L-shaped slender reinforced concrete columns", Mag. Concr. Res. 46:169 (1994), 257-267.

Received 11 Apr 2009. Revised 17 Jun 2009. Accepted 3 Jul 2009.

CHEN ZHI-HUA: zhchen@tju.edu.cn

College of Civil Engineering, Tianjin University, Tianjin 300072, China

http://www2.tju.edu.cn/colleges/civil/list.php?cid=23

RoNG BIN: tjerobincn@hotmail.com

College of Civil Engineering, Tianjin University, Tianjin 300072, China

Apostolos FAfitis: fafitis@asu.edu

Department of Civil and Environmental Engineering, Arizona State University, Tempe, AZ 85287, United States

http://engineering.asu.edu/people/35093 